\title{
Study of Traffic Volume and its Safety Measurement at Dadabari Circle, Career Point University, Kota
}

\author{
Raj Pratap Singh\#, Himanshu Tekwani”, Bhavesh Joshi^*, Pratheek Sudhakaran^^ and Jitendra Singh^^ \\ \#Civil Engineering Department Career Point University of Engineering, Kota, Rajasthan, India \\ ^Amity School of Architecture \& Planning, Amity University of Engineering, Jaipur, Rajasthan, India
}

Received 10 Nov 2017, Accepted 15 Jan 2018, Available online 25 Jan 2018, Vol.8, No.1 (Jan/Feb 2018)

\begin{abstract}
The knowledge of traffic volume is an important basic input required for planning, analysis and operation of roadway systems. A significant effort has been made in order to study the Traffic Volume of Dadabari Chauraha. For better understanding of the present status of traffic flow at the junction, traffic survey is conducted. The safe and time efficient movement of the people and goods is dependent on Traffic flow, which is directly connected to the traffic characteristics. In Traffic Flow we have to consider generally three parameters, Volume, Speed, and Capacity. While as a traffic volume may be defined as the number of vehicles passing a given section of road or traffic lane per unit time will be inappropriate when several types of vehicles with widely varying static and dynamic characteristics are comprised in the traffic. Due to mixed nature of traffic it gets difficult to accommodate all the kinds of traffic on these roads. The basic problem arises during the peak hours of the day when the traffic volume is highest on the road. The interaction between moving vehicles under such heterogeneous traffic condition is highly complex. The problem of measuring volume of such kind of traffic has been addressed by converting the different types of vehicles into equivalent passenger cars and expressing the volume in terms of Passenger Car Unit (PCU) per hour. Calculation of Passenger Car Units (PCU's) for different vehicle types had been made. For a wide range of traffic volume and roadway conditions indicate that the PCU value of a vehicle significantly changes with change in traffic volume and width of roadway. some of the remedial measures to improve the traffic safety in the region such as widening the road, changing 4-lane to 6-lane or by providing more public transport can be recommended based on the outcomes of the work.
\end{abstract}

Keywords: Traffic Control, PCU, Heterogeneous Traffic, Traffic Volume

\section{Introduction}

Traffic volume are conducted to determine the number of vehicle at given location volume is simply the number of vehicles passing a section of a roadway. It is calculated by the number of vehicle passing section of a road by the regular time intervals. Heterogeneous traffic addressed by converting different types of vehicle in passenger cars equivalent $\&$ its volume can be expressed passenger car unit (PCU) Per hour. Intersection Manual count of 15- min intervals used to find out the traffic volume.

\section{Review of literature}

Main problem is the speed flow relationship. The vehicle all types produce different impedance which is varied to the static \& dynamic characteristics. Hence by simply adding the vehicle does not give the accurate or

*Corresponding author's ORCID ID: 0000-0002-7919-8405 DOI: https://doi.org/10.14741/ijcet.v8i01.10892 authentic speed flow relationship. So, to come out from this situation passenger car is adopted as a standard vehicle and term is used a passenger car unit (PCU). Before finding out the traffic volume we have to traffic survey of particular given place the purpose of traffic survey is, traffic monitoring management, model calibration \& traffic control, etc.

\section{Purpose of Study}

To find out the traffic volume at particular location is necessary to fulfil the following purpose:

1) To determine the traffic volume passing in and out to the given area.

2) Traffic monitoring and traffic control.

\section{Methodology}

Firstly, we study the traffic field to have traffic volume \& speed data in Dadabari chauraha. We don't have a 
instrument so we used the manual method at evening time the rush is more so we used indirect method while in morning we used the direct manual method.

Manual counting method

i) Direct method.

ii) Indirect method.

Direct Method: - By this method data can be collected immediately we can have obtained the traffic volume as well as vehicle classification. At evening time, we have used this method.

Indirect Method: - In this method the traffic volume count is collected by the video camera. Video is captured \& after that data is collected by rewinding.

\section{Objectives}

The main objective of the traffic study is as follow

- To find out various traffic volume on selected section on Dadabari Chauraha road.

- To find out the traffic flow pattern on weekdays and weekends for 15 minutes interval variation

- How to minimize the traffic through different ideas.

Location: We have chosen the location from V-Mart to SS Dairy at Dadabari Chauraha.

By standing the side of the road different vehicles were counted by group members.

We have selected one member who was in charge of time, he commanded us when we have to Stop and Start our time watch.

Date: Data for volume study was collected on $3^{\text {rd }}$ Nov 2017.It was Friday and it was a week day.

Time: Time of data collection for volume study was divided in four times and the time interval is 15 minutes.

Weather Condition: It was Sunny day.

Observation: Classified vehicle counts

Duration: 15 minutes (short count)

Equipment: Mobile Camera (Video recorder) Stopwatch, rough copy

\section{Number of enumerator: Two}

Traffic Characteristics: The different type of vehicles presents at Dadabari Chauraha:

1) Motorized two wheelers (M.T.W) which includes bikes and scooters.

2) Motorized three wheelers (M.Th. W) which includes auto rickshaws and tempos.
3) Four wheelers which includes cars and jeeps.

4) Light commercial vehicles (L.C.V) which includes small vans and four wheelers.

5) Truck

6) Bus

7) Bicycle

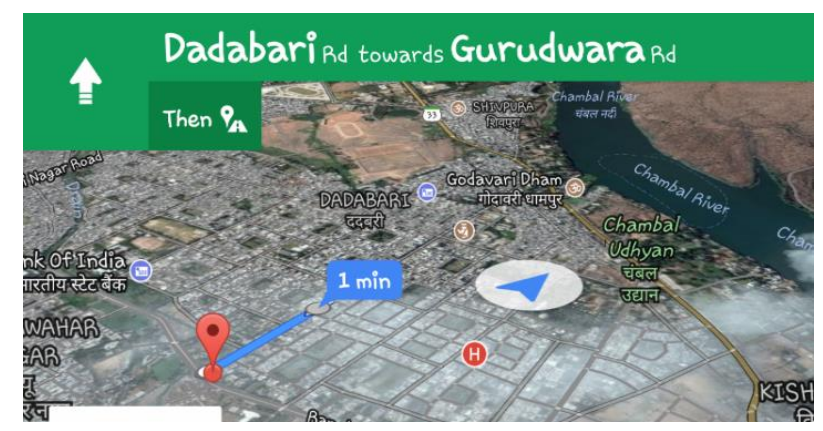

Fig 3.1: Map of Dadabari Chauraha

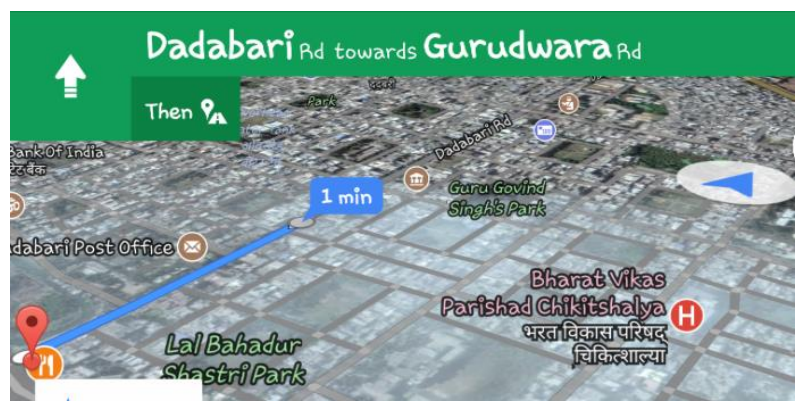

Fig 3.2: Location of traffic volume counts

\section{Data collection and analysis}

The data is collected after carefully studying the location area. The study was conducted on a sunny day when the pavement was dry and no repairing were going at that time.

\section{Method used for volume study}

For the calculation of volume at our location area both manual and video camera method(photographic) were used. A smart phone camera was used to make of traffic at given location. The smart phone was mounted on a tripod stand with the opening of camera. By this the video is made in 15 minutes interval. Later this video is reminded and viewed again for the data analysis with the help of Smart phones, Smart T.V. and Computers. From the applied manual method these are the following data were observed:

Table1: PCU factors used for traffic signal design

\begin{tabular}{|c|c|}
\hline Vehicles & PCU Factors \\
\hline Car & 1 \\
\hline 3-wheeler & 1 \\
\hline 2-wheeler & 0.5 \\
\hline Bus/Truck & 3 \\
\hline Rickshaw & 1.5 \\
\hline Cycle & 0.5 \\
\hline Tractor & 4.5 \\
\hline LCV & 1.5 \\
\hline
\end{tabular}


Table2: No. of vehicle (V-mart to SS dairy)

\begin{tabular}{|c|c|c|c|c|}
\hline $\begin{array}{c}\text { No. of } \\
\text { vehicle }\end{array}$ & $\begin{array}{c}8: 00- \\
8: 15 \mathrm{am}\end{array}$ & $\begin{array}{c}1: 00- \\
1: 15 \mathrm{pm}\end{array}$ & $\begin{array}{c}4: 00- \\
4: 15 \mathrm{pm}\end{array}$ & $\begin{array}{c}8: 00- \\
8: 15 \mathrm{pm}\end{array}$ \\
\hline 2W & 499 & 430 & 542 & 594 \\
\hline 3W & 65 & 56 & 72 & 58 \\
\hline 4W & 96 & 75 & 88 & 95 \\
\hline HV & 5 & 7 & 3 & 2 \\
\hline Pedestrian & 63 & 42 & 54 & 72 \\
\hline
\end{tabular}

Table3: Converted no. of vehicle (PCU)

\begin{tabular}{|c|c|c|c|c|}
\hline $\begin{array}{c}\text { Type of } \\
\text { vehicle }\end{array}$ & $\begin{array}{c}\text { No. of } \\
\text { vehicle }\end{array}$ & PCE & PCU & $\%$ PCU \\
\hline 2W & 8260 & 0.5 & 4130 & 61.14 \\
\hline 3W & 1004 & 1 & 1004 & 14.86 \\
\hline 4W & 1416 & 1 & 1416 & 20.96 \\
\hline HV & 68 & 3 & 204 & 3.020 \\
\hline Total & 10748 & - & - & 100 \\
\hline
\end{tabular}

\section{Conclusion}

It can be concluded that vehicle composition most of the vehicle in the traffic stream were motor cycles. Percentage of two wheelers is higher than other vehicle. After volume study as we observed that more traffic is in the peak hours i.e. in morning and evening.

\section{References}

Bhavneet Singh, Dr. Tripta Goyal (2015) Study of Traffic Volume and Level of Service of Panjab University, Chandigarh Journal of Engineering Research and Application ISSN: 2248-9622, Vol. 5, Issue 7.

Ishant Sharma, Dr. Pardeep K. Gupta (2015) Study of automatic traffic signal system for chandigarh ISSN: 2277-9655 (I20R), Publication Impact Factor: 3.785

Himanshu bharadwaj, Saurab sharma, Raj sharma, Vinod kumar (2016) Traffic Volume Study of Sitapura, Jaipur SSRG International Journal of Civil Engineering (SSRGIJCE) - volume 3 Issue 7 - July 2016.

IRC-106-1990 Guidelines for capacity of urban roads in plain areas.

HCM, 2010, Highway, Capacity Manual.

Lateral Distribution of Mixed on Two-Lan Roads, Journal of Transportation Engineering, ASCE, 597-600.

Dimension and weight of road design vehicles IRC: 31983.

Dey. P.P, Chandra S., Gangopadhaya, S (2006). Lateral Distribution Lateral Distribution of Mixed Traffic on Two-LaneRoads. Journal of Transportation Engineering, ASCE, 597-600. 